\title{
Optimizing rearing and welfare in Senegalese sole (Solea senegalesensis) broodstock: Effect of ambient light intensity and handling time on stress response
}

\author{
Filipe Figueiredo ${ }^{\mathrm{a}, \mathrm{b}}$, Cláudia Aragão ${ }^{\mathrm{a}, \mathrm{c}}$, Wilson Pinto ${ }^{\mathrm{a}, \mathrm{d}}$, Maria Teresa Dinis ${ }^{\mathrm{a}}$, \\ Catarina C.V. Oliveira ${ }^{\mathrm{a}, \mathrm{c}, *}$ \\ ${ }^{a}$ CCMAR, Centro de Ciências do Mar, Campus de Gambelas, edf. 7, 8005-139 Faro, Portugal \\ ${ }^{\mathrm{b}}$ Norwegian College of Fishery Science, University of Tromsø, Troms $\emptyset$ N-9037, Norway \\ ${ }^{\mathrm{c}}$ Universidade do Algarve, Campus de Gambelas, 8005-139 Faro, Portugal \\ d SPAROS, Lda., Área Empresarial de Marim, Lote C, 8700-221 Olhão, Portugal
}

\section{A R T I C L E I N F O}

\section{Keywords:}

Cortisol

Locomotor activity

Fish welfare

Daily rhythms

G1 breeders

\begin{abstract}
A B S T R A C T
Broodstock rearing conditions and handling procedures should be optimized in aquaculture species in order to benefit fish welfare and guarantee optimal conditions for spawning. In teleosts, basal cortisol levels display daily rhythms, oscillating along the $24 \mathrm{~h}$ of the day. In this sense, handling fish at different moments of the day may lead to different stress responses. The present study aimed at investigating the optimal rearing conditions for Senegalese sole broodstock, considering ambient light intensity and handling time. The optimal light intensity (50, 100 or $200 \mathrm{~lx}$ ) was investigated by measuring fish cortisol levels and monitoring locomotor activity rhythms under each intensity tested. Results showed a significant increase in cortisol levels of fish exposed to $200 \mathrm{~lx}$, when compared to values obtained under $100 \mathrm{~lx}$, accompanied by changes in locomotor activity rhythms in both tanks under study. These results suggested that $200 \mathrm{~lx}$ may be too high as light intensity for this species, whereas $100 \mathrm{~lx}$ seems to be more adequate. Also, daily rhythms of stress response were investigated in breeders from different origins (Wild and first generation, G1). Basal cortisol levels and cortisol stress response after an acute stressor (air exposure) were monitored at two distinct moments of the day (Mid-Light and Mid-Dark). Basal levels were higher during the day in the wild group, while G1 fish seemed to have lost the daily fluctuations in basal cortisol plasma levels, as well as their daily rhythms of locomotor activity. Both groups showed lower stress responses during night-time, an indication that this is an adequate period of the day to handle this species. Senegalese sole breeders born in captivity presented more pronounced stress responses when compared to wild fish, reflecting their different life history in terms of stress challenges.
\end{abstract}

\section{Introduction}

Senegalese sole, Solea senegalensis, is among the most interesting and promising species for European marine aquaculture diversification (Imsland et al., 2003; Morais et al., 2016). While its culture potential has been periodically affirmed by different authors (Howell, 1997; Dinis et al., 1999; Imsland et al., 2003), intensive production has been slow to take off (Morais et al., 2016). Several studies have contributed to the knowledge of the species biology and requirements for production, namely in larval rearing, nutritional requirements and metabolism (Aragão et al., 2004; Morais et al., 2005; Martins et al., 2011; Bonacic et al., 2016), genetics, pathologies and skeletal malformations (Gavaia et al., 2002; Soares et al., 2002; Porta et al., 2006; Fatsini et al., 2016).
Despite this large body of information available on Senegalese sole rearing, broodstock reproduction problems persist, with low fertilization rates (Chauvigné et al., 2016), irregular or incomplete spawning (Agulleiro et al., 2006) and complete reproductive failure (Carazo et al., 2011) being reported in first generation (G1) individuals. The inability of G1 individuals to naturally reproduce in captivity (García-López et al., 2006; Guzmán et al., 2008) forces the aquaculture industry to rely only on wild broodstock. This situation is unsustainable, as wild Senegalese sole are already endangered due to fishing pressure (Morais et al., 2016) and preservation of its spawning stock biomass is paramount for the recovery of the species.

Photoperiod and temperature cycles play key roles in determining the natural spawning behaviour of Solea senegalensis' broodstock

\footnotetext{
* Corresponding author at: CCMAR, Centro de Ciências do Mar, Campus de Gambelas, edf. 7, 8005-139 Faro, Portugal.

E-mail address: ccoliveira@ualg.pt (C.C.V. Oliveira).
} 
(Oliveira et al., 2009a, b; Oliveira et al., 2011), but light intensity has been overlooked in research involving its rearing environment (Imsland et al., 2003; Cañavate et al., 2006). The specificity of light perception (Migaud et al., 2006; Oliveira et al., 2007) means that lighting systems should be tailored to suit species requirements and preferences.

In an aquaculture environment, altered environmental conditions and routine practices such as handling, sorting, grading or transport, can induce stress in fish that has detrimental effects to health and development (Barton and Iwama, 1991; Bonga, 1997; Guerriero and Ciarcia, 2006; Mosconi et al., 2006; Brijs et al., 2018). Exposure to stressful factors triggers a coping mechanism as a cascading physiological response. A steep rise in cortisol, the main corticosteroid in fish and the most commonly measured indicator of stress (Small et al., 2008), aims to increase circulating glucose levels to compensate for higher energy demand (Mommsen et al., 1999; Mosconi et al., 2006). Ultimately, stressors result in changes in performance and fitness, causing reduced resistance to pathogens, inhibition of growth and, especially, reproductive failure (Barton and Iwama, 1991; Bonga, 1997; Barton, 2002; Tort, 2011). According to Schreck (2010), cortisol negatively affects egg quality, ovulation/spermiation, mating behaviour and mate selection. Broodstock welfare is crucial in solving issues preventing natural reproduction, so, providing animals with favourable husbandry conditions can positively influence the success of a production cycle. This can be achieved by minimizing the impact of stress factors such as inadequate lighting or handling.

Fish welfare has been broadly discussed recently (Saraiva et al., 2019), however there is still disagreement about its definition (Huntingford and Kadri, 2009). Definitions of welfare generally vary between the function-based (fish can adapt to its environment and is in good health, with all its biological systems working appropriately), the nature-based (is able to lead a natural life, expressing the same kinds of behaviour as it would in the wild) and the feelings-based (animal is free of negative experiences such as pain, fear and hunger and has access to positive experiences, such as social companionship) approaches (Huntingford et al., 2006; Huntingford and Kadri, 2009; Saraiva et al., 2019). Human activities such as aquaculture compromise fish welfare but the effects depend on the species and life-history stage. The resulting harm to fish welfare is a cost that must be minimized and weighed against the benefits of the activity concerned (Huntingford et al., 2006).

Fish display rhythms of varying frequencies in almost every physiological activity (Singh et al., 2009). Locomotion, growth, reproduction and immune physiology rhythms are synchronized by extrinsic stimuli that change or reset their phase (Cermakian and Sassone-Corsi, 2002; Volkoff et al., 2009). As cortisol secretion also follows a daily rhythm in fish (López-Olmeda et al., 2009; Oliveira et al., 2013), it can be hypothesized that the intensity of stress response is also time-dependent. This leads to the assumption that acute stress response can have a lower impact on an individual when handled at a specific time of day. Indeed, the modulation of stress response in relation to the time of day has been observed in green sturgeon (Acipenser medirostris) (Lankford et al., 2003), sea bream (Sparus aurata) (Vera et al., 2014) and Senegalese sole (López-Olmeda et al., 2013). The latter authors described different cortisol responses according to the time of day in juvenile G1 soles, however there is no available information for adult breeders, nor on the existence of differences between captivity bred (G1) and wild individuals. It is known that inappropriate environmental conditions seriously compromise fish larvae welfare and early development (Villamizar et al., 2011). In Senegalese sole, light strongly influenced the development of the biological clock, modifying the onset of daily activity rhythms and bringing out different behavioural responses in larvae (Blanco-Vives et al., 2012). Furthermore, light intensity has also proven to have an effect on fish aggression on other species (Carvalho et al., 2013; Lopes et al., 2018). Such facts may have implications in the circadian system of the adult animal, thus differences between G1 and Wild soles in terms of cortisol response rhythms deserve to be pursued, to test a possible effect of species domestication
(Pasquet, 2019; Saraiva et al., 2019). Taking into consideration that the use of individuals bred in captivity as broodstock is important towards the development of a species' aquaculture, it is essential that good welfare conditions are attained.

With all this in mind, the present research aims to investigate the optimal rearing conditions for Senegalese sole broodstock, considering light intensity and handling time. Optimal light intensity $(50,100$ or $2001 \mathrm{x}$ ) has been investigated for wild breeders, by measuring fish cortisol basal levels and monitoring locomotor activity rhythms, while daily rhythms of stress response were characterized for G1 and wild breeders, through the evaluation of stress response at different times of day.

\section{Material and methods}

Experimental procedures were conducted in accordance with the guidelines of the European Directive (2010/63/EU) and Portuguese legislation for the use of laboratory animals. The Centre of Marine Science (CCMAR) facilities and their staff are certified to house and conduct experiments with live animals (Group-C licenses by the Direção Geral de Alimentação e Veterinária, Ministério da Agricultura, Florestas e Desenvolvimento Rural, Portugal). Whenever necessary, experimental procedures were performed under anaesthesia with 2-phenoxyethanol and every effort was made to minimize suffering at all stages.

\subsection{Animals and housing}

All experiments took place at the CCMAR Research Station Ramalhete (Faro, Portugal), using the existing Senegalese sole broodstock, previously acclimated to captivity conditions. All wild individuals were captured along the Portuguese south coast, and had at least one year of acclimation to our rearing facilities. Fish were kept indoors in four circular, $3 \mathrm{~m}^{3}$ tanks, with $1500 \mathrm{l}$ of seawater. Tanks were supplied with flow-through gravel-filtered seawater at a constant flow ( $\pm 4 \mathrm{~L} / \mathrm{min}$ ). A total of 40 Solea senegalensis (10 per tank) individually identified with a PIT-tag system (ID100 Implantable Transponder, Trovan, The Netherlands) were used for all experiments. For the first experiment, two out of four tanks were used (A1 and A2), containing wild origin individuals long adapted to captivity conditions, with similar fish sizes (1167.8 $\pm 737.8 \mathrm{~g})$ and sex ratios (1:1). In the second experiment, the other two Senegalese sole stocks were used: tank B1, containing wild individuals $(530 \pm 52.9 \mathrm{~g})$ and tank B2, containing first generation breeders - G1 (1308 $\pm 776.5 \mathrm{~g})$.

Prior to the start of Experiment 1, all four tanks were covered with a light proof black polyethylene tarpaulin, supported by a polyvinyl chloride structure, and equipped with a lighting system (AquaBeam 600 Ultra, Tropical Marine Centre ${ }^{\mathrm{TM}}$, Portugal) on the inside. Each tarpaulin had a flap that could be opened and fully closed, providing access to the interior of the tanks for cleaning and feeding. The lighting system was connected to a controller (AquaRay Control, Tropical Marine Centre ${ }^{\mathrm{TM}}$, Portugal), that switched lights on/off at a pre-set time. The system was confirmed to be lightproof by measuring light levels inside each tank with a lux meter. All tanks were exposed to natural conditions of photoperiod and temperature before the start of the trials.

Hydrographic parameters such as dissolved oxygen (mg/L), temperature $\left({ }^{\circ} \mathrm{C}\right)$ and salinity (ppt) were measured daily to monitor the quality of the rearing water. Individuals were fed $3 \%$ of biomass 6 out of 7 days of the week during the morning, with food alternating between semi-wet feed (Sparos Lda., Portugal), polychaete Nereis virens (Inovsea Lda., Portugal) or frozen mussel (Mytilus spp. kernel, assorted suppliers) injected with a vitamin and mineral premix (formulation developed by Sparos Lda.).

\subsection{Experiment 1. Optimization of rearing conditions - light intensity}

The objective of the first experiment was to determine the optimal 
light intensity for Senegalese sole broodstock rearing. Fish in the two tanks (A1 and A2) were exposed to a simulated natural autumn photoperiod (SNP) for the Faro region (Portugal) (oscillating between 13:11 to $10: 14 \mathrm{~L}: \mathrm{D})$ throughout the whole experimental period. Photoperiod was adjusted every $2^{\text {nd }}$ or $3^{\text {rd }}$ day. Average water temperature during the experimental period was $19.58 \pm 1.90^{\circ} \mathrm{C}$.

During the first month (September), light intensity (white light) was set to 50 lx. After this period, blood samples were collected as described below. Light intensity was increased to $100 \mathrm{~lx}$ for the second month (October), after which blood samples were collected again. In the third part of this experiment, light intensity was increased to $200 \mathrm{~lx}$ for one more month (November) and blood sampling took place at the end. Experiments were performed without coinciding with Solea senegalensis' spawning season to avoid possible confounding factors from reproductive behaviour or hormones (Anguis and Cañavate, 2005).

\subsubsection{Sampling}

All sampling procedures were performed in the morning, at the same time in relation to dawn, avoiding a masking effect from the daily fluctuation of cortisol in blood (Oliveira et al., 2013). Before sampling, all individuals of each tank were anesthetized in seawater containing $800 \mathrm{ppm}$ of 2-phenoxyethanol (77699 Fluka, Sigma-Aldrich). When unresponsive to touch, approximately $1 \mathrm{ml}$ of blood was extracted by caudal puncture using heparinized syringes and transferred to heparinized microtubes on ice. All samples were collected within 5 min, counting from the moment the fish were removed from the tank, to prevent a rise in cortisol levels due to sampling stress (Costas et al., 2011). Blood was then centrifuged at $3000 \times g$ for $15 \mathrm{~min}$ at room temperature and plasma frozen at $-80^{\circ} \mathrm{C}$ until posterior analysis.

\subsubsection{Locomotor activity assessment}

In order to evaluate how increasing light intensities would affect fish behaviour, locomotor activity was continuously monitored and recorded in both tanks, enabling the quantification of the daily rhythms of locomotor activity.

Prior to the experiment, each tank had been equipped with an infrared motion-sensor photocell, installed on the inside wall, $5 \mathrm{~cm}$ from the bottom, and pointing towards the centre of the tank. Photocells were individually connected to a relay in a small electrical circuit, and from there to a motherboard (USB-1024HLS, Measurement Computing ${ }^{\mathrm{TM}}$, Norton, Massachusetts, USA) connected to a computer. Every time an individual interrupted the infrared beam emitted by the photocell, an electrical output signal was produced, which was then converted into a digital signal by the motherboard, and stored in $10 \mathrm{~min}$ bins using software specially designed for that purpose (DIO98USB, University of Murcia, Spain) (Oliveira et al., 2017; Vera et al., 2009).

\subsection{Experiment 2. Daily rhythms of stress response in Solea senegalensis}

The second experiment aimed to describe stress response rhythms of Senegalese sole breeders in relation to their origin (wild $v s \mathrm{G} 1$ ), using animals held in tanks B1 and B2. Considering that cortisol daily rhythms may be affected by the daily patterns of behaviour (LópezOlmeda et al., 2009), a pre-trial was performed to characterize the circadian system of these stocks in the first place. Daily activity rhythms were attained by monitoring locomotor activity continuously in both tanks during one month prior to the beginning of Experiment 2. As described for Experiment 1, activity was monitored using the previously settled photo-cellular system.

\subsubsection{Sampling}

Basal cortisol levels were assessed for both groups (wild and G1) at Mid-Light (ML), the mid-point between dawn and dusk, and Mid-Dark (MD), the equivalent point, but between dusk and dawn, leaving a three weeks interval between samplings, to allow fish recovery from handling procedures. Afterwards, post-stress cortisol levels were determined at the same time points (ML and MD), this time leaving a two month interval between samplings to allow stress recovery. As in the previous experiment, trials took place between September and January, as to not coincide with Solea senegalensis' spawning season, thus avoiding possible confounding factors. Water temperature during the experimental period was $17.16 \pm 3.93^{\circ} \mathrm{C}$, and light intensity at the water surface was set at $100 \mathrm{~lx}$.

Sampling procedure for both ML and MD basal levels was similar to that described for Experiment 1: blood was withdrawn from the caudal vein of anaesthetised fish within $5 \mathrm{~min}$ from the moment the fish were collected from the tank. For the post-stress ML and MD sampling points, a stressor (air exposure) was applied before blood sampling: individuals were netted from the rearing tank and left out of the water for $3 \mathrm{~min}$ and then were returned to the experimental tanks. Blood samples were collected one hour after the applied stressor (Costas et al., 2011), following the same procedure described above. Sampling was performed under white light during the day and under a dim red light during the night, when Senegalese sole's heads were also covered with aluminium foil (Oliveira et al., 2007).

\subsubsection{Cortisol analysis}

All plasma cortisol levels were measured using a commercial cortisol Enzyme-Linked Immunosorbent Assay (ELISA) kit (IBL International $\mathrm{GmbH}$, Germany), previously validated for Senegalese sole elsewhere (Oliveira et al., 2013). For basal cortisol levels (experiments 1 and 2), a kit with a sensitivity of $0.5 \mathrm{ng} / \mathrm{mL}$, and intra- and inter-assay coefficient variation (CV) of 4.7 and $8.2 \%$, respectively, was used, while post-stress cortisol samples (experiment 2) were analysed with a similar kit but with a sensitivity of $2.5 \mathrm{ng} / \mathrm{mL}$, and intra- and inter-assay CV of 7.5 and $17 \%$, respectively.

\subsubsection{Statistical analysis}

Statistical analysis and data plotting were performed using $R(\mathrm{R}$ Core Team, 2018), GraphPad (GraphPad Software, La Jolla, California, USA) and chronobiology specific software El Temps (Prof. A. Díez Noguera, University of Barcelona, Spain). Results were expressed as mean \pm standard error of the mean (SEM). A Shapiro-Wilk normality test (shapiro.test command in R) (R Core Team, 2018) was used to assess data normality in all data.

Cortisol basal plasma levels under different light intensities (Experiment 1) were tested by fitting a Linear Mixed Effects Regression model to the data, from the lme $4 \mathrm{R}$ package (lmer command in R) (Bates et al., 2015), with treatment and tank as fixed effects, and individuals as a random effect. The model was also tested with both tank as random effect, with no change in results. This model was then analysed with an ANOVA (anova command in R) (R Core Team, 2018), to identify possible significant differences in the fixed effects. Because the ANOVA revealed significant differences between treatments $(p<0.05)$, post hoc comparisons were done using the emmeans package (emmeans command in R) (Lenth, 2019), with Tukey's method (emmeans' default) for $p$-value adjustment. Regarding Experiment 2, despite using the same procedure for statistical analysis as in Experiment 1, Basal and Stress data were analysed separately.

In order to identify behaviour rhythmicity patterns for each group (Experiments 1 and 2), locomotor activity data was plotted in the form of actograms and mean waveforms using the software El Temps and Sigmaplot ${ }^{\circledR}$. An actogram is a graphical representation of the locomotor activity along successive day cycles double-plotted on successive horizontal lines, while a mean waveform represents the mean activity along the $24 \mathrm{~h}$ cycle. Senegalese sole were either categorized as diurnal or nocturnal, depending on when (i.e., day or night, respectively) locomotor activity occurred the most. Significant differences between mean diurnal and nocturnal activity counts were evaluated using a Mann-Whitney rank sum test (significant threshold of $p<0.05$ ). When no statistical differences between diurnal and nocturnal activity means were observed for a certain period, the animals were considered 


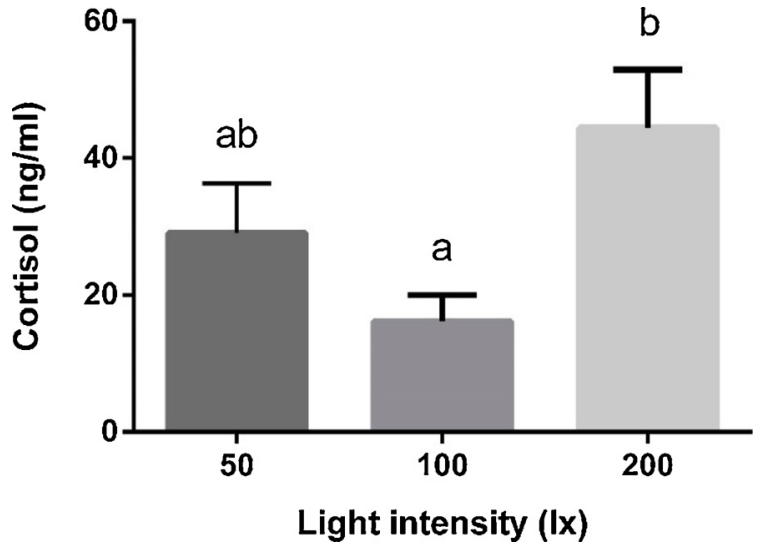

Fig. 1. Cortisol basal levels (Mean \pm SEM) of Senegalese sole breeders after one month exposure to each of three different ambient light intensities (50, 100 and $200 \mathrm{~lx}$ ) during daytime. Different letters represent significant statistical differences between light intensities $(\mathrm{p}<0.05)$.

arrhythmic (Vera et al., 2009). Statistical significance of activity daily rhythms was evaluated by COSINOR analysis using the same software: "Amplitude" (one-half the peak-to-trough variation), "mesor" (time series mean), and "acrophase" (peak time relative to the time scale) were determined by least-squares approximation of cosine function (significant threshold of $\mathrm{p}<0.05$ ) (Cornelissen, 2011; Díez, 2007).

\section{Results}

\subsection{Experiment 1. Optimization of rearing conditions - light intensity}

Basal cortisol levels varied between the three sampling points of the experiment, coinciding with increasing light intensities during the day period of a SNP (Fig. 1). After one month of exposure to $50 \mathrm{~lx}$, cortisol plasma levels were $29.09 \pm 1.93 \mathrm{ng} / \mathrm{mL}$, decreasing slightly to $16.22 \pm 0.99 \mathrm{ng} / \mathrm{ml}$ under $100 \mathrm{~lx}$ light intensity. The increase of light intensity to $200 \mathrm{~lx}$ lead to a significant rise $(\mathrm{p}<0.05)$ in cortisol production $(44.47 \pm 2.18 \mathrm{ng} / \mathrm{mL})$.

Concerning locomotor activity patterns, when experimental groups were held under $50 \mathrm{~lx}$ during daytime, the actograms (Fig. 2a, d) and mean waveforms (Fig. 2c, f) showed higher activity during daylight hours in both tanks ( 82 and $86 \%$ respectively for A1 and A2), starting at $7 \mathrm{~h} 10$, decreasing from $20 \mathrm{~h} 00$ onwards and staying at a minimum during the night hours. Counts per 10 min averaged at 2.81 and 4.93 during the day for $\mathrm{A} 1$ and $\mathrm{A} 2$ individuals, respectively, while during the night that average decreased to 0.70 and 0.95 . Such difference in activity levels between day and night periods was confirmed to be statistically significant for both tanks ( $\mathrm{p}<0.001)$. The COSINOR analyses (Fig. 2b, e) corroborated the rhythmicity in locomotor activity in both tanks $(\mathrm{p}<0.001$ ): peak acrophase times were at $12 \mathrm{~h} 13$ and $14 \mathrm{~h} 30$, respectively for $\mathrm{A} 1$ and $\mathrm{A} 2$, mesor was 1.86 and 3.01 counts $/ 10 \mathrm{~min}$ and amplitudes were 1.70 and 2.73 counts $/ 10 \mathrm{~min}$.

Under 100 lx, locomotor activity (Fig. 3) followed a similar pattern to that observed under $50 \mathrm{~lx}$, with higher activity registered during the day (70 and 74\%) and a clear decrease after sunset, as evidenced by the significant statistical differences in activity levels between day $(2.40$ and 5.63 counts $/ 10 \mathrm{~min})$ and night hours (1.00 and 1.80 counts/ $10 \mathrm{~min}$ ) ( $\mathrm{p}<0.001$ ). COSINOR analysis (Fig. 3c, f) proved once more the significance of the daily rhythm in both tanks $(\mathrm{p}<0.001)$ and, as in the previous phase of the trial, acrophase occurred earlier in A1 (10h36) individuals than in A2 (14h00). Mesor was 1.65 and 3.58 counts/10 min and amplitude 1.17 and 2.94 counts/10 min, respectively for A1 and A2.

In the last phase of the trial, when animals were reared under $200 \mathrm{~lx}$ during daytime, locomotor activity daily pattern changed in tank A1: activity increased during night time (68\%) and exhibited its peak before sunrise (Fig. 4a, b, c). Significant differences between day (2.03 counts/ $10 \mathrm{~min}$ ) and night ( 3.13 counts/10 $\mathrm{min}$ ) mean locomotor activity were seen $(\mathrm{p}<0.05)$ and the COSINOR analysis (Fig. 4b) indicated rhythmicity, with acrophase occurring at $5 \mathrm{~h} 40$, a mesor of 2.95 counts/ $10 \mathrm{~min}$ and an amplitude of 2.17 counts $/ 10 \mathrm{~min}$. As for the A2 individuals, daily pattern was not so clear, as suggested by the actogram (Fig. 4d) and mean waveform (Fig. 4f). No statistically significant differences were detected between day (1.50 counts/10 $\mathrm{min}, 52 \%)$ and night activity levels (1.00 counts/10 $\mathrm{min}, 48 \%$ ), thus this tank was considered arrhythmic. However, COSINOR analysis (Fig. 4e) revealed significant rhythmicity ( $\mathrm{p}<0.001)$, with acrophase taking place at $8 \mathrm{~h} 36$, a mesor of 1.26 counts $/ 10 \mathrm{~min}$ and an amplitude of 0.69 counts/ $10 \mathrm{~min}$.

\subsection{Experiment 2. Daily rhythms of stress response in Solea senegalensis}

\subsubsection{Activity patterns characterization}

Wild Senegalese sole (Fig. 5a, b, c) demonstrated a clear daily rhythm in locomotor activity, with higher activity levels observed during the day (95\%), averaging at 16.36 counts/10 min. After sunset, that activity decreased to a minimum of 1.15 counts/ 10 min, making this discrepancy between day and night statistically significant ( $\mathrm{p}<0.001$; Mann-Whitney rank sum). Regarding the G1 individuals, locomotor activity occurred either during day (3.00 counts/10 min) or night (2.60 counts $/ 10 \mathrm{~min})$ periods, as illustrated by the actogram (Fig. 5d) and mean waveform (Fig. 5f). Since no statistical differences were observed between day and night activity levels ( $\mathrm{p}<0.05)$, these fish were considered arrhythmic. The different shapes of the mean waveforms of both groups is reflected on the COSINOR analysis results (Fig. 5b, e): whilst in Wild individuals a significant daily rhythm was described ( $\mathrm{p}<0.001$, acrophase located at $11 \mathrm{~h} 27$, mesor and amplitude 9.86 and 11.57 counts $/ 10 \mathrm{~min}$, respectively), the same did not happen in the G1 group.

\subsubsection{Cortisol stress response rhythms}

The determination of basal and post-stress cortisol levels at ML and MD revealed a clear influence of time of day (Fig. 6). Basal levels seemed to follow opposite rhythms in relation to fish origin: in wild individuals, levels were more elevated during the day $(60.22 \pm 18.31$ vs $13.22 \pm 3.89 \mathrm{ng} / \mathrm{mL}$ ), while for G1 there was a tendency for higher plasma concentrations during night time $(19.63 \pm 4.45$ vs $7.07 \pm 3.28 \mathrm{ng} / \mathrm{mL}$ ) (Fig. 6a). The application of the statistical analysis did not reveal an influence on basal cortisol levels either of fish origin or time of day.

Post-stress cortisol levels (Fig. 6b) were shown to be influenced by both factors tested (origin, $\mathrm{p}<0.01$; time of day, $\mathrm{p}<0.001$ ). First generation individuals had a significantly higher cortisol response in both samplings $(597.65 \pm 20.19$ and $256.27 \pm 47.40 \mathrm{ng} / \mathrm{mL}$, respectively for ML and MD) when compared to wild individuals $(289.87 \pm 50.76$ and $70.00 \pm 23.47 \mathrm{ng} / \mathrm{mL}$, respectively for ML and MD samplings), and stress response was always greater during daytime within each origin group. The largest increase in cortisol occurred in G1 individuals sampled during the day, with post-stress levels being 84 times higher than basal concentrations.

\section{Discussion}

The importance of defining the optimal rearing conditions for Senegalese sole broodstock is well illustrated in the present paper by the impact that ambient light intensity has on the perceived welfare of this species. This research also highlights the necessity of taking the time of day into consideration when handling Senegalese sole broodstock in order to minimize the stress response.

The relation between metabolic and behavioural results in the first experiment seems to suggest that $200 \mathrm{~lx}$ is above the optimum light 
(a)

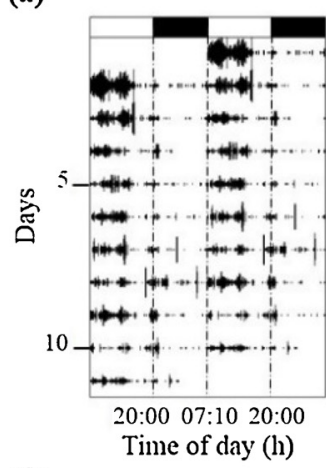

(d)

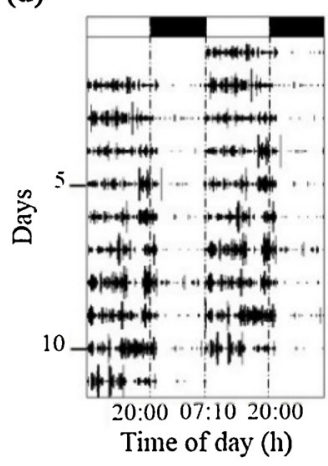

(b)

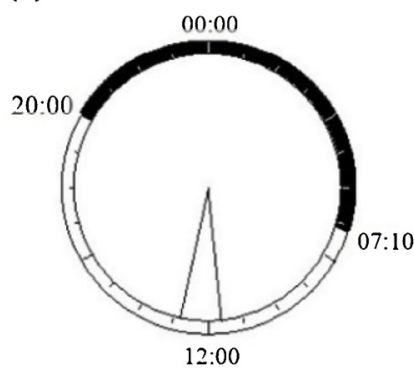

(e)

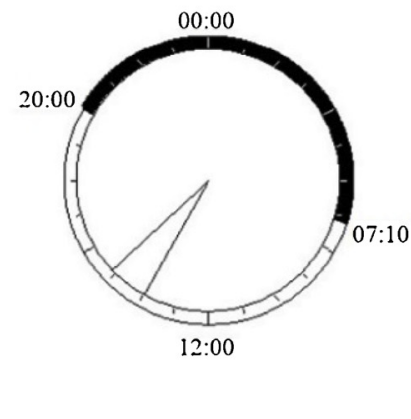

(c)

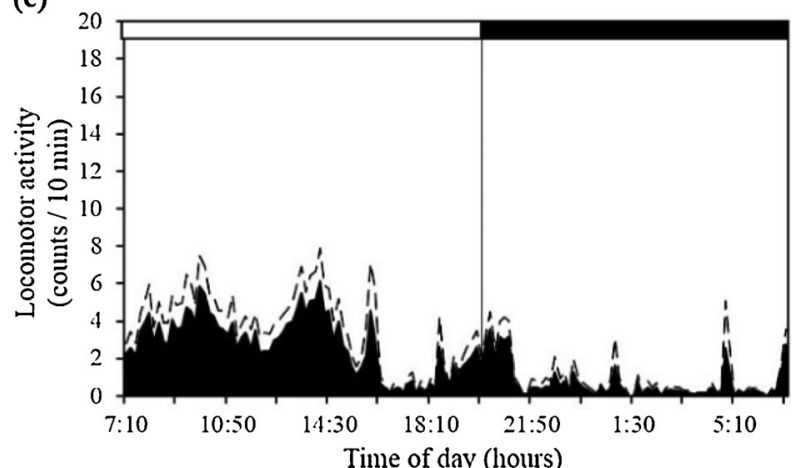

(1)

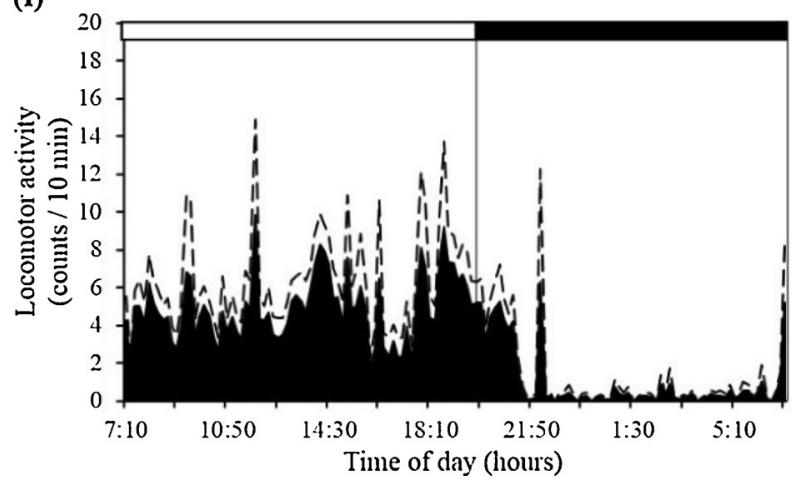

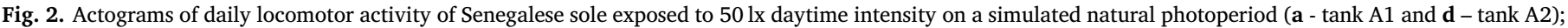

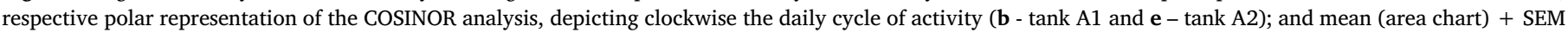

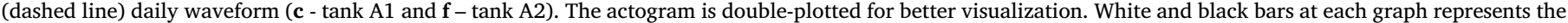
light (day) and dark (night) periods, respectively. Triangle in COSINOR graphs delimits the acrophase confidence interval.

(a)

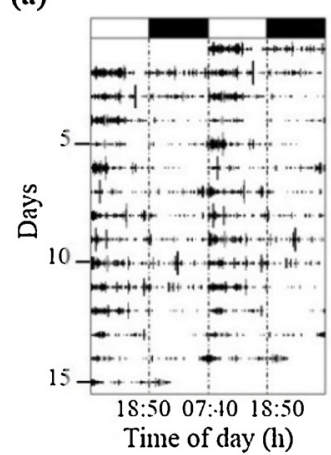

(d)

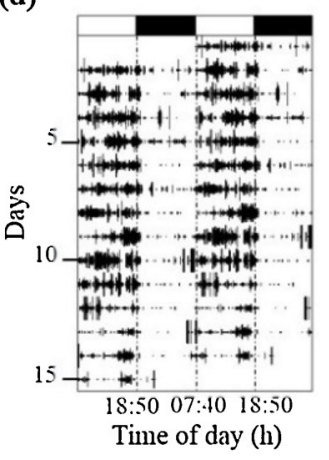

(b)

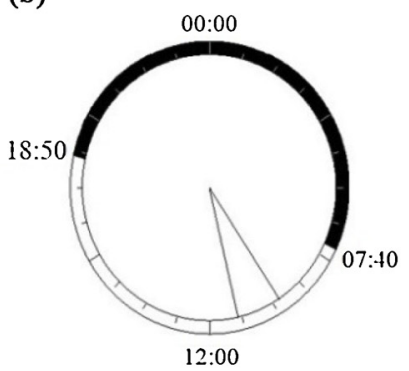

(e)

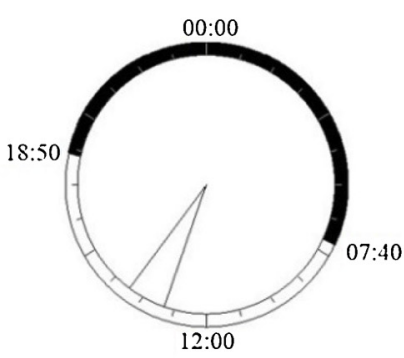

(c)

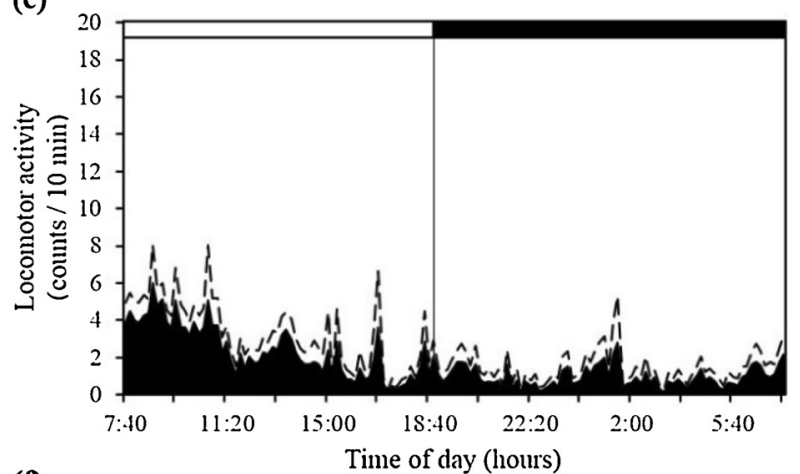

(f)

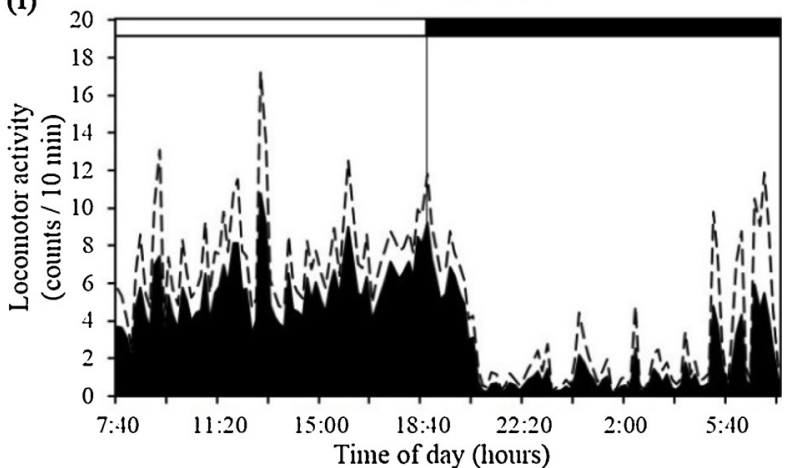

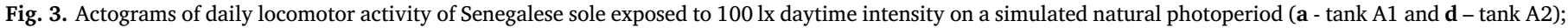

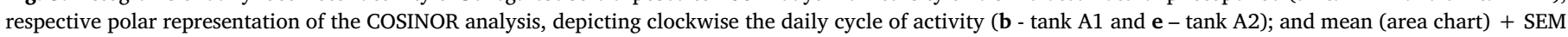

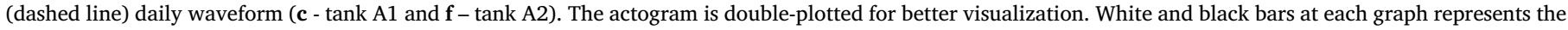
light (day) and dark (night) periods, respectively. Triangle in COSINOR graphs delimits the acrophase confidence interval. 
(a)

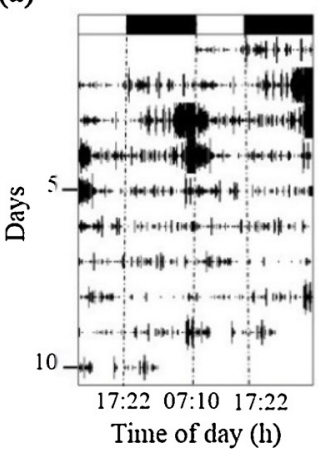

(d)

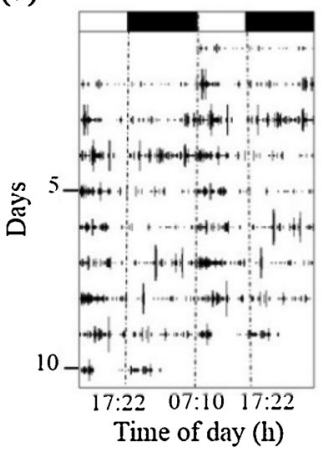

(b)

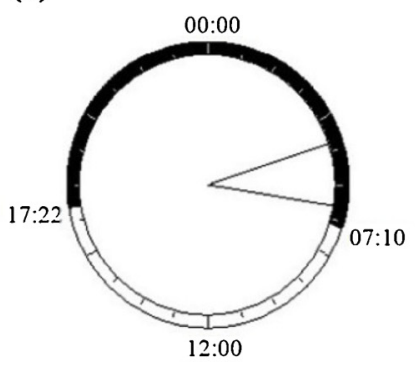

(e)

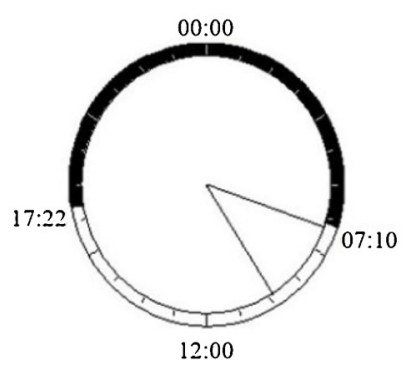

(c)

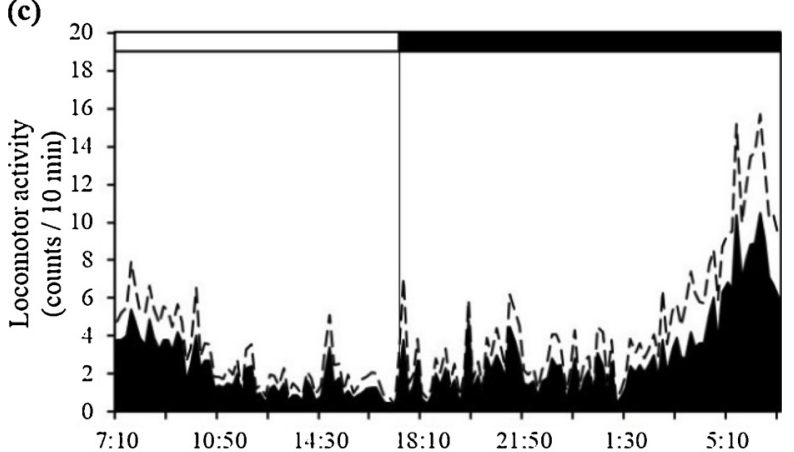

(f)

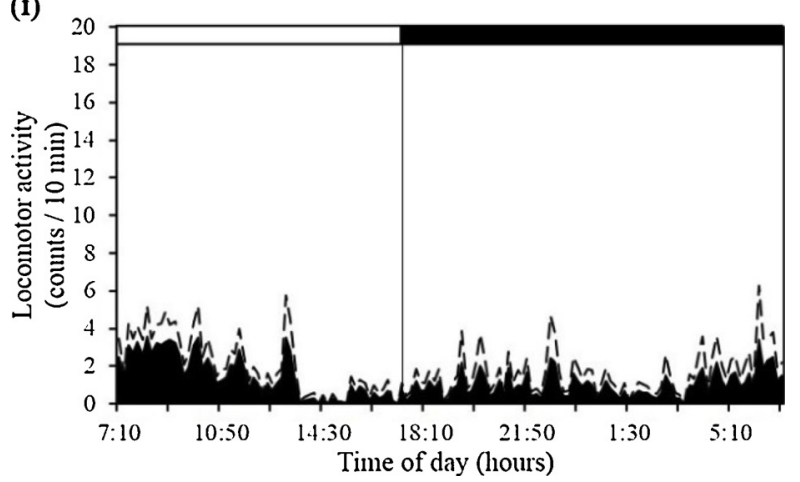

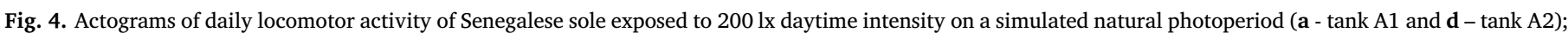

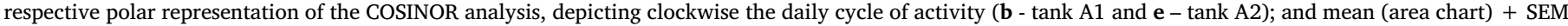

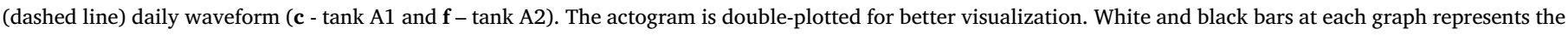
light (day) and dark (night) periods, respectively. Triangle in COSINOR graphs delimits the acrophase confidence interval.

(a)

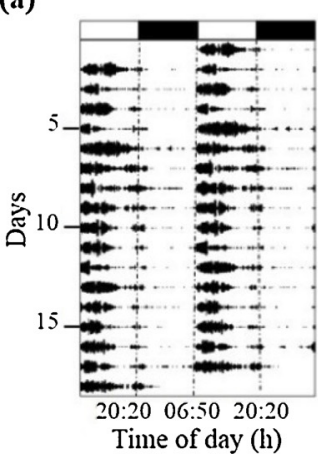

(d)

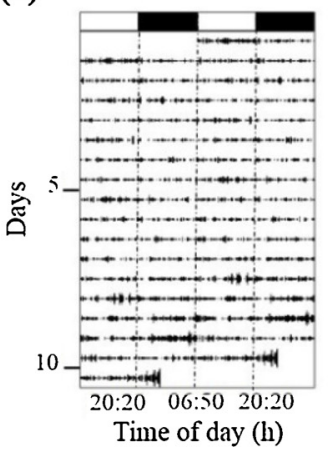

(b)

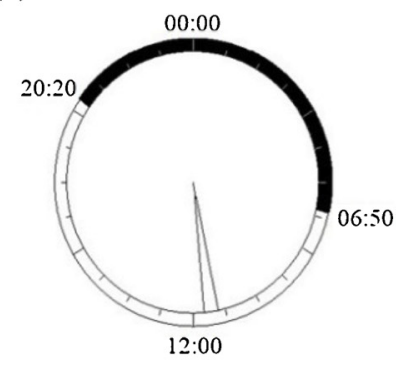

(e)

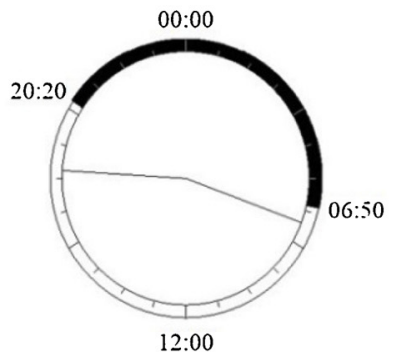

(c)

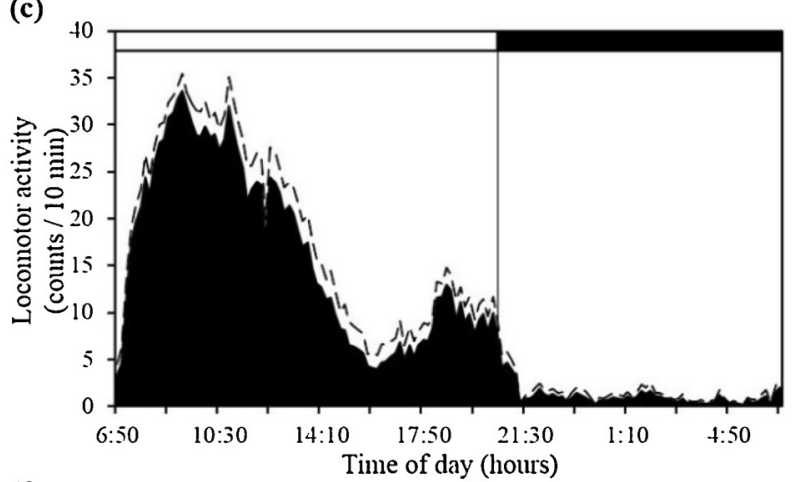

(f)

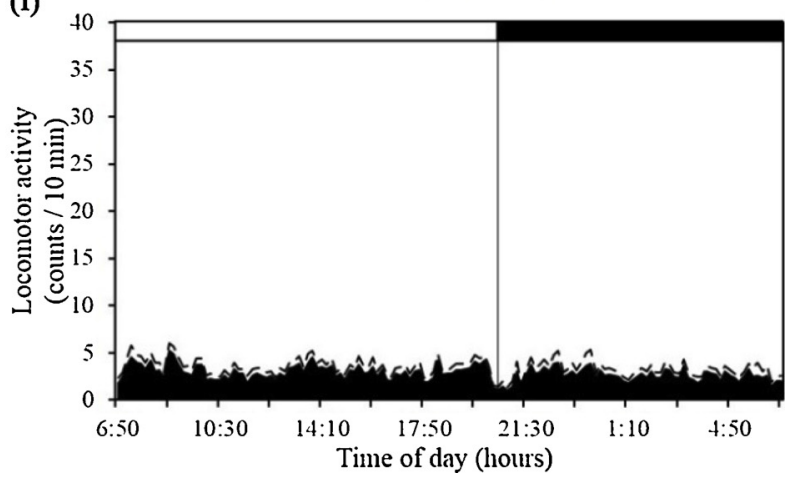

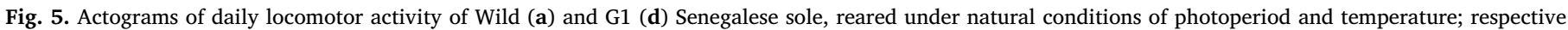

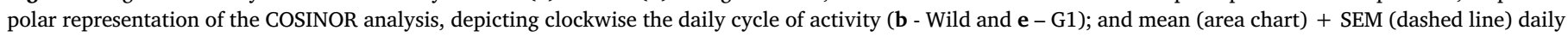

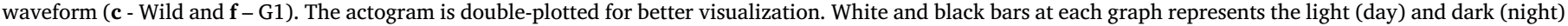
periods, respectively. Triangle in COSINOR graphs delimits the acrophase confidence interval. 

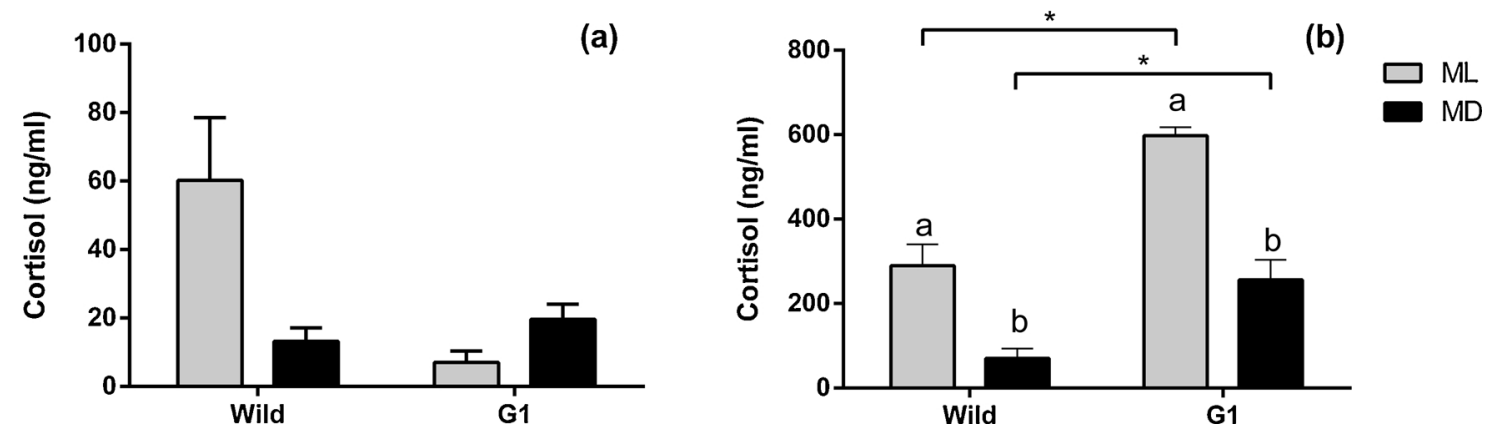

Fig. 6. Cortisol basal (a) and post-stress levels (b) (Mean \pm SEM) in wild and G1 Senegalese sole sampled at different times of day (Mid-Dark, MD and Mid-Light, ML). Different letters represent significant statistical differences between time points, within each fish group (p $<0.005)$; * represents significant statistical differences between fish groups, for the same time point $(\mathrm{p}<0.05)$.

threshold for Solea senegalensis broodstock, by comparison with intensities of 50 and $100 \mathrm{~lx}$. When fish were exposed to this high light intensity a significant increase in basal levels of plasma cortisol was observed, accompanied by an alteration of behavioural rhythms (one tank became arrhythmic, and the other switched from diurnal to nocturnal behaviour), indicating adjustments at the physiological level. Results of locomotor activity should however be interpreted cautiously, since photocell information could be produced by only part of the fish in the tank, and due to the variability observed between tanks under 200 lx. Basal plasma cortisol concentrations in Senegalese sole were previously observed to follow a daily rhythm (Oliveira et al., 2013) and values obtained under $100 \mathrm{~lx}(16.22 \pm 3.56 \mathrm{ng} / \mathrm{mL})$ are coincident with morning values observed by those authors. After the $200 \mathrm{~lx}$ period, cortisol concentration increased to $44.46 \pm 7.86 \mathrm{ng} / \mathrm{mL}$, which could be associated with a condition of chronic stress. Previous research revealed that cortisol levels around $30 \mathrm{ng} / \mathrm{ml}$ or above in Senegalese sole held at high stocking density (Costas et al., 2008), or under an osmotic challenge (Arjona et al., 2009; Aragão et al., 2008), are related with chronic stress. Comparisons should, however, be cautious due to the diversity in fish ages and sizes among studies. Under $50 \mathrm{~lx}$, plasma cortisol averaged $29.09 \pm 6.97 \mathrm{ng} / \mathrm{mL}$, an intermediate value that did not present significant differences with either sampling points, though it seems high for the species when compared with the same studies cited above for chronic stress. In line with our results, very high or very low light intensities were seen to cause elevated plasma cortisol or glucose levels in orange spotted grouper (Epinephelus coioides) (Wang et al., 2013), blunt snout seabream (Megalobrama amblycephala) (Tian et al., 2015) and starry flounder (Platichthys stellatus) (Bögner et al., 2018), reinforcing the idea that inadequate light intensity can impair fish welfare in aquaculture.

As to locomotor activity, both tanks showed diurnal activity under 50 or $100 \mathrm{~lx}$, in contrast to what has been described in the species (Bayarri et al., 2004; Oliveira et al., 2013). Such a behavioural profile has been previously monitored and associated with this group of fish, due to long term adaptation to the morning feeding schedule (Oliveira et al., personal communication), which is a very potent synchronizer of fish daily rhythms (López-Olmeda, 2017). In a captive environment, Senegalese sole broodstock is known to habituate to husbandry routines, synchronizing its peak of activity with feeding time during the day (Carazo et al., 2013; Morais et al., 2016). During the periods fish were exposed to 50 and $100 \mathrm{~lx}$ intensities, the COSINOR parameters (acrophase, mesor and amplitude) did not show major alterations. The change in diurnal daily rhythms occurred under $200 \mathrm{~lx}$, indicating an instability of the circadian system under such light intensity. Other species also showed modifications in their behaviour after a change in ambient light intensity; e.g. in Nile tilapia (Oreochromis niloticus) individual aggression markedly decreased at lower light intensities compared to stronger illumination (Carvalho et al., 2013), reinforcing the importance of using a species specific suitable light intensity.
In a wide range of teleost species, including flatfishes, light intensity has been seen to influence juvenile growth in association with several other physiological parameters, such as feed intake, survival rate, immune response or dietary nutrient composition, according to species preferences (Kozłowski et al., 2010; Wang et al., 2013; Tian et al., 2015; Bögner et al., 2018). In all cases, better growth was observed at lower light intensities, sometimes associated with differences in stress markers. Also, in fish larvae, evidences were found on the influence of light intensity on growth (common sole, Solea solea L., Bonvini et al., 2016) or aggression (matrinxã, Brycon amazonicus, Lopes et al., 2018). All the above strengthens the notion that light environment in aquaculture should be carefully considered for each life stage and according to species preferences, assuring optimal welfare conditions and, ultimately, product quality and productivity. Species specific environmental preferences are believed to be an adaptation to each ecological niche and therefore fish are predisposed to perform better under specific light environments. In the wild, Senegalese sole is a benthic species, inhabiting bottom areas in estuaries and sandy or muddy grounds with shallow waters. These environments have varying light penetrations according to depth and turbidity of water, and species have to adapt to such a challenging environment. Senegalese sole is very sensitive to dim levels of illumination during the night and has a very plastic circadian system (Oliveira et al., 2007, 2009a), all these in agreement with this preference for intermediate ambient light intensities during the day. In common sole, light appeared to be more necessary to aid feed intake during the pelagic phase of larvae, but once sensory capacities improve along with metamorphosis, less light is needed during the benthic phase (Bonvini et al., 2016). Based on the present results, we may suggest that the optimal light intensity for Senegalese sole broodstock rearing is $100 \mathrm{~lx}$.

The second experiment revealed pronounced differences in the circadian system of Senegalese sole breeders born in captivity when compared to wild specimens, both at behavioural and physiological levels. Wild sole presented a very clear daily rhythm in locomotor activity, being predominantly active during the day, in synchronization with feeding time as discussed above. In terms of cortisol concentration, both basal and post-stress values were greater during the day, in agreement with previous findings in the species (López-Olmeda et al., 2013; Oliveira et al., 2013), regardless of the locomotor activity rhythms. On the other hand, first generation animals did not show clear daily rhythms in locomotor activity nor in basal cortisol concentrations, indicating a disruption of the circadian system development, possibly caused by husbandry during early larval development, as previously suggested for reproduction dysfunction problems (Howell et al., 2011; Morais et al., 2016). Production conditions used at early stages to promote feeding intake (high constant temperatures and long darkness periods), might be compromising the normal development of both the brain-pituitary-gonad (BPG) and the hypothalamus-pituitary-interrenal (HPI) axes, as a consequence of the domestication process. Senegalese 
sole is considered to be at the beginning of the domestication process (level 3 out of 5) (Teletchea and Fontaine, 2014), and only after one generation, this effects are already evident. The circadian system is responsible for transducing environmental cues, passing timely information to the organism and entraining animals' rhythms at different levels (daily, lunar, seasonal) (Falcón et al., 2010). When the early development of such system is disrupted, all rhythms may be compromised, namely behavioural, endocrinal and reproductive. The G1 group, however, did show daily fluctuations in terms of cortisol response to an acute stress challenge, which was significantly higher during the day, as seen elsewhere in juveniles of this species (LópezOlmeda et al., 2013), highlighting the importance of the time of day when handling Senegalese sole. To the best of our knowledge, the existence of daily rhythms in stress response is barely explored in fish, with only a few studies available in other species (Lankford et al., 2003; Vera et al., 2014). However, this could be an interesting tool to minimize the effect of unavoidable stressors under captive conditions (sampling, sorting, fishing, etc.), both for farming and research purposes, thus increasing fish welfare. Handling Senegalese sole during the night period will always induce a minor stress response.

The group of Senegalese sole born and raised under aquaculture conditions showed more pronounced stress response than their wild counterparts, either when exposed to the acute stressor during the day or during the night. As to basal levels, the opposite happened during the day, when groups were compared. Such differences likely reflect their different origin and life history. Wild fish were captured as adults, thus experienced the dangers and challenges of a natural environment (escaping from predators, searching for food, hiding from a storm, etc), which are not present in a protected and predictable environment as an aquaculture system, and this history can be determinant of subsequent corticosteroid status (Pankhurst, 2011). This is especially true for Senegalese sole, which is a benthonic species, inhabiting the bottom of the tanks, thus perceiving minimally the disturbances of surrounding environment. In rainbow trout (Oncorhynchus mykiss) it was seen that brief stress episodes, or cortisol applied very early in ontogeny, resulted in a reduced cortisol stress response at 5 months of age, suggesting that different stress responses among adults might reflect their experience during ontogeny, as well as heritable traits (Auperin and Geslin, 2008). Even cortisol treatment of females prior to spawning induced an effect on the offspring of wild largemouth bass (Micropterus salmoides), which resulted in attenuated cortisol response to an acute stressor, together with less anxiety, exploratory behaviour, boldness and aggression of juveniles (Redfern et al., 2017). Both these evidences support the hypothesis that non-genetic factors acting early in life will organize or imprint physiological systems in fish (Auperin and Geslin, 2008), in line with our results, which reflected different stress responses according to fish life history. All this suggests that early exposure of fish to mild stress can be beneficial to juvenile and adult stages, as it can reduce their sensitivity to stressful events, being more adapted to the ongoing environmental demand and perturbations (Auperin and Geslin, 2008).

The present study represents the first description of the influence of light intensity on broodstock welfare in aquaculture of a flatfish species, suggesting that either too high or too low ambient intensities are not the most adequate. For Senegalese sole, $100 \mathrm{~lx}$ seems to be the most suitable light intensity in terms of basal cortisol levels and daily rhythms of locomotor activity. Under captivity, such assessment is an extremely important issue in fish welfare management, as according to each species' habitat preferences, optimal environmental conditions may vary. Our results also demonstrated that Senegalese sole breeders from different origins (wild $v s$ G1) presented different stress response rhythms, reflecting their life history in terms of exposure to stress challenges. However, both groups had lower stress responses during nighttime, thus this is the period of the day more suited to handle this species. Senegalese sole breeders born in captivity seemed to have lost the daily fluctuations in basal cortisol plasma levels, as well as their daily rhythms of locomotor activity, revealing that also the circadian system and the HPI axis could be impaired due to rearing conditions, along with the known disruption in the BPG axis of these fish. More research is needed into the ontogeny of such systems under different conditions, to develop better selection programs to obtain breeders more fitted to cope with stress challenges in an aquaculture environment.

\section{Acknowledgements}

This research has been financed by the FP7 project Prospawn (Seventh Framework Programme for Research and Technological Development, FP7/SME/2008/1). CCMAR is funded by the Portuguese Foundation for Science and Technology (Ministry of Science and Higher Education, Portugal and European Social Funds) through project UID/ Multi/04326/2019. CO and CA were funded by national funds through FCT - Portuguese Foundation for Science and Technology, I.P., in the framework of the Transitional Rule (DL 57/2016/CP1361/CT0007 and DL 57/2016/CP1361/CT0033, respectively). Authors would also like to thank João Reis, from Ramalhete Experimental Station, for technical assistance and Rita Teodósio, for her help during fish sampling.

\section{References}

Agulleiro, M.J., Anguis, V., Cañavate, J.P., Martínez-Rodríguez, G., Mylonas, C.C., Cerdà, J., 2006. Induction of spawning of captive reared Senegal sole (Solea senegalensis) using different administration methods for gonadotropin-releasing hormone agonist. Aquaculture 257, 511-524.

Anguis, V., Cañavate, J.P., 2005. Spawning of captive Senegal sole (Solea senegalensis) under a naturally fluctuating temperature regime. Aquaculture 243, 133-145.

Aragão, C., Conceição, L.E.C., Fyhn, H.J., Dinis, M.T., 2004. Estimated amino acid requirements during early ontogeny in fish with different life styles: gilthead seabream (Sparus aurata) and Senegalese sole (Solea senegalensis). Aquaculture 242, 589-605.

Aragão, C., Corte-Real, J., Costas, B., Dinis, M.T., Conceição, L.E., 2008. Stress response and changes in amino acid requirements in Senegalese sole (Solea senegalensis Kaup 1858). Amino Acids 34 (1), 143-148.

Arjona, F.J., Vargas-Chacoff, L., Ruiz-Jarabo, I., Gonçalves, O., Páscoa, I., Martín del Río, M.P., Mancera, J.M., 2009. Tertiary stress responses in Senegalese sole (Solea senegalensis Kaup, 1858) to osmotic challenge: implications for osmoregulation, energy metabolism and growth. Aquaculture 287 (3-4), 419-426.

Auperin, B., Geslin, M., 2008. Plasma cortisol response to stress in juvenile rainbow trout is influenced by their life history during early development and by egg cortisol content. Gen. Comp. Endocrinol. 158 (3), 234-239.

Barton, B.A., Iwama, G.K., 1991. Physiological changes in fish from stress in aquaculture with emphasis on the response and effects of corticosteroids. Annu. Rev. Fish Dis. $3-26$.

Barton, B.A., 2002. Stress in fishes: a diversity of responses with particular reference to changes in circulating corticosteroids. Integr. Comp. Biol. 42, 517-525.

Bates, D., Maechler, M., Bolker, B., Walker, S., 2015. Fitting linear mixed-effect models using lme4. J. Stat. Softw. 67 (1), 1-48.

Bayarri, M.J., Muñoz-Cueto, J.A., López-Olmeda, J.F., Vera, L.M., Rol de Lama, M.A., Madrid, J.A., Sánchez-Vázquez, F.J., 2004. Daily locomotor activity and melatonin rhythms in Senegal sole (Solea senegalensis). Physiol. Behav. 81 (4), 577-583.

Blanco-Vives, B., Aliaga-Guerrero, M., Cañavate, J.P., García-Mateos, G., Martín-Robles, A.J., Herrera-Pérez, P., Muñoz-Cueto, J.A., Sánchez-Vázquez, F.J., 2012. Metamorphosis induces a light-dependent switch in Senegalese sole (Solea senegalensis) from diurnal to nocturnal behavior. J. Biol. Rhythms 27, 135-144.

Bonacic, K., Campoverde, C., Gómez-Arbonés, J., Gisbert, E., Estevez, A., Morais, S., 2016. Dietary fatty acid composition affects food intake and gut-brain satiety signaling in Senegalese sole (Solea senegalensis, Kaup 1858) larvae and post-larvae. Gen. Comp. Endocrinol. 79-94.

Bonga, S.E.W., 1997. The stress response in fish. Physiol. Rev. 77 (3), 591-625.

Bonvini, E., Parma, L., Gatta, P.P., Mandrioli, L., Sirri, R., Martelli, G., Nannoni, E., Mordenti, A., Bonaldo, A., 2016. Effects of light intensity on growth, feeding activity and development in common sole (Solea solea L.) larvae in relation to sensory organ ontogeny. Aquac. Res. 47 (6), 1809-1819.

Bögner, M., Schwenke, C., Gürtzgen, T., Bögner, D., Slater, M.J., 2018. Effect of ambient light intensity on growth performance and diurnal stress response of juvenile starry flounder (Platichthys stellatus) in recirculating aquaculture systems (RAS). Aquac. Eng. 83, 20-26.

Brijs, J., Sandblom, E., Axelsson, M., Sundell, K., Sundh, H., Huyben, D., Broström, R., Anders, K., Berg, C., Gräns, A., 2018. The final countdown: continuous physiological welfare evaluation of farmed fish during common aquaculture practices before and during harvest. Aquaculture 495, 903-911.

Cañavate, J.P., Zerolo, R., Fernández-Díaz, C., 2006. Feeding and development of Senegal sole (Solea senegalensis) larvae reared in different photoperiods. Aquaculture 258 (1-4), 368-377.

Carazo, I., Martin, I., Hubbard, P., Chereguini, O., Mañanós, E., Canário, A., Duncan, N., 2011. Reproductive behaviour, the absence of reproductive behaviour in cultured (G1 generation) and chemical communication in the Senegalese Sole (Solea 
senegalensis). Indian J. Sci. Technol. 4 (S8), 96-97 Proceedings of the 9th International Symposium on Reproductive Physiology of Fish, Cochin, India.

Carazo, I., Norambuena, F., Oliveira, C., Sánchez-Vázquez, F.J., Duncan, N.J., 2013. The effect of night illumination, red and infrared light, on locomotor activity, behaviour and melatonin of Senegalese sole (Solea senegalensis) broodstock. Physiol. Behav. 118, 201-207.

Carvalho, T.B., Mendonça, F.Z., Costa-Ferreira, R.S., Gonçalves-de-Freitas, E., 2013. The effect of increased light intensity on the aggressive behavior of the Nile tilapia, Oreochromis niloticus (Teleostei: cichlidae). Zoologia Curitiba (Curitiba) 30, 125-129.

Cermakian, N., Sassone-Corsi, P., 2002. Environmental stimulus perception and control of circadian clocks. Curr. Opin. Neurobiol. 12, 359-365.

Chauvigné, F., Fatsini, E., Duncan, N., Ollé, J., Zanuy, S., Gómez, A., Cerdà, J., 2016. Plasma levels of follicle-stimulating and luteinizing hormones during the reproductive cycle of wild and cultured Senegalese sole (Solea senegalensis). Comp. Biochem. Physiol., Part A Mol. Integr. Physiol. 191, 35-43.

Cornelissen, G., 2011. Cosinor-based rhythmometry. Theor. Biol. Med. Model. 11-16.

Costas, B., Aragão, C., Mancera, J.M., Dinis, M.T., Conceição, L.E.C., 2008. High stocking density induces crowding stress and affects amino acid metabolism in Senegalese sole Solea senegalensis (Kaup 1858) juveniles. Aquac. Res. 39 (1), 1-9.

Costas, B., Conceição, L.E.C., Aragão, C., Martos, J.A., Ruiz-Jarabo, I., Mancera, J.M., Afonso, A., 2011. Physiological responses of Senegalese sole (Solea senegalensis Kaup, 1858) after stress challenge: effects on non-specific immune parameters, plasma free amino acids and energy metabolism. Aquaculture 316 (1-4), 68-76.

Díez, A., 2007. Representación grafica y análisis de datos en cronobiología. In: Madrid, J.A., Rol de Lama, M.A. (Eds.), Cronobiología básica y clínica. Editec@red S.L., Madrid, pp. 84-121.

Dinis, M.T., Ribeiro, L., Soares, F., Sarasquete, C., 1999. A review on the cultivation potential of Solea senegalensis in Spain and in Portugal. Aquaculture 176, 27-38.

Falcón, J., Migaud, H., Muñoz-Cueto, J.A., Carrillo, M., 2010. Current knowledge on the melatonin system in teleost fish. Gen. Comp. Endocrinol. 165, 469-482.

Fatsini, E., Bautista, R., Manchado, M., Duncan, N.J., 2016. Transcriptomic profiles of the upper olfactory rosette in cultured and wild Senegalese sole (Solea senegalensis) males. Comp. Biochem. Physiol. Part D Genomics Proteomics 20, 125-135.

García-López, A., Pascual, E., Sarasquete, C., Martínez-Rodríguez, G., 2006. Disruption of gonadal maturation in cultured Senegalese sole Solea senegalensis Kaup by continuous light and/or constant temperature regimes. Aquaculture 261, 789-798.

Gavaia, P.J., Dinis, M.T., Cancela, M.L., 2002. Osteological development and abnormalities of the vertebral column and caudal skeleton in larval and juvenile stages of hatchery-reared Senegal sole (Solea senegalensis). Aquaculture 211, 305-323.

Guerriero, G., Ciarcia, G., 2006. Stress biomarkers and reproduction in fish. In: In: Reinecke, M., Zaccone, G., Kapoor, B.G. (Eds.), Fish Endocrinology Volume 2. Science Publishers, Enfield, New Hampshire, pp. 665-692.

Guzmán, J.M., Norberg, B., Ramos, J., Mylonas, C.C., Mañanós, E.L., 2008. Vitellogenin, steroid plasma levels and spawning performance of cultured female Senegalese sole (Solea senegalensis). Gen. Comp. Endocrinol. 156 285-29.

Howell, B.R., 1997. A re-appraisal of the potential of the sole, Solea solea (L.), for commercial cultivation. Aquaculture 155, 355-365.

Howell, B., Prickett, R., Cañavate, P., Mañanos, E., Dinis, M.T., Conceição, L., Valente, L.M.P., 2011. Sole farming: there or thereabouts!. Aquac. Int. 36 (3), 42-45.

Huntingford, F.A., Adams, C., Braithwaite, V.A., Kadri, S., Pottinger, T.G., Sandøe, P., Turnbull, J.F., 2006. Current issues in fish welfare. J. Fish Biol. 68, 332-372.

Huntingford, F.A., Kadri, S., 2009. Taking account of fish welfare: lessons from aquaculture. J. Fish Biol. 75, 2862-2867.

Imsland, A.K., Foss, A., Conceição, L.E.C., Dinis, M.T., Delbare, D., Schram, E., Kamstra, A., Rema, P., White, P., 2003. A review of the culture potential of Solea solea and S. Senegalensis. Rev. Fish Biol. Fish. 13, 379-408.

Kozłowski, M., Zakęś, Z., Szczepkowski, M., Wunderlich, K., Piotrowska, I., Szczepkowska, B., 2010. Impact of light intensity on the results of rearing juvenile pikeperch, Sander lucioperca (L.), in recirculating aquaculture systems. Arch. Polish Fish. 18 (2), 77-84.

Lankford, S.E., Adams, T.E., Cech, J.J.Jr., 2003. Time of day and water temperature modify the physiological stress response in green sturgeon, Acipenser medirostris. Comp. Biochem. Physiol. Part A Mol. Integr. Physiol. 135, 291-302.

Lenth, R., 2019. Emmeans: Estimated Marginal Means, Aka Least-squares Means. R Package Version 1.4. https://CRAN.R-project.org/package $=$ emmeans.

Lopes, A.C.C., Villacorta-Correa, M.A., Carvalho, T.B., 2018. Lower light intensity reduces larval aggression in matrinxã, Brycon amazonicus. Behav. Process. 151, 62-66.

López-Olmeda, J.F., Montoya, A., Oliveira, C., Sánchez-Vázquez, F.J., 2009. Synchronization to light and restricted-feeding schedules of behavioral and humoral daily rhythms in gilthead sea bream (Sparus aurata). Chronobiol. Int. 26, 1389-1408.

López-Olmeda, J.F., Blanco-Vives, B., Pujante, I.M., Wunderink, Y.S., Mancera, J.M., Sánchez-Vázquez, F.J., 2013. Daily rhythms in the hypothalamus-pituitary-interrenal axis and acute stress responses in a teleost flatfish, Solea senegalensis. Chronobiol. Int. 30, 530-539.

López-Olmeda, J.F., 2017. Nonphotic entrainment in fish. Comp. Biochem. Physiol. Part A Mol. Integr. Physiol. 203, 133-143.

Martins, D.A., Engrola, S., Morais, S., Bandarra, N., Coutinho, J., Yúfera, M., Conceição, L.E.C., 2011. Cortisol response to air exposure in Solea senegalensis post-larvae is affected by dietary arachidonic acid-to-eicosapentaenoic acid ratio. Fish Physiol. Biochem. 37, 733-743.

Migaud, H., Taylor, J.F., Taranger, G.L., Davie, A., Cerd, J., Carrillo, M., Hansen, T., Bromage, N., 2006. A comparative ex vivo and in vivo study of day and night perception in teleosts species using the melatonin rhythm. J. Pineal Res. 41, 42-52.

Mommsen, T.P., Vijayan, M.M., Moon, T.W., 1999. Cortisol in teleosts: dynamics, mechanisms of action, and metabolic regulation. Rev. Fish Biol. Fish. 9 (3), 211-268.
Morais, S., Koven, W., Rønnestad, I., Dinis, M.T., Conceição, L.E.C., 2005. Dietary protein/lipid ratio affects growth and amino acid and fatty acid absorption and metabolism in Senegalese sole (Solea senegalensis Kaup 1858) larvae. Aquaculture 246, $347-357$.

Morais, S., Aragão, C., Cabrita, E., Conceição, L.E.C., Constenla, M., Costas, B., Dias, J., Duncan, N., Engrola, S., Estevez, A., Gisbert, E., Mañanós, E., Valente, L.M.P., Yúfera, M., Dinis, M.T., 2016. New developments and biological insights into the farming of Solea senegalensis reinforcing its aquaculture potential. Rev. Aquac. 8, 227-263.

Mosconi, G., Cardinaletti, G., Carotti, M., Palermo, F., Soverchia, L., Polzonetti-Magni, A. M., 2006. Neuroendocrine mechanisms regulating stress response in cultured teleost species. In: Reinecke, M., Zaccone, G., Kapoor, B.G. (Eds.), Fish Endocrinology, volume 2. Enfield, New Hampshire: Science Publishers, pp. 693-720.

Oliveira, C., Ortega, A., López-Olmeda, J.F., Vera, L.M., Sánchez-Vázquez, F.J., 2007. Inflence of constant light and darkness, light intensity, and light spectrum on plasma melatonin rhythms in Senegal sole. Chronobiol. Int. 24, 615-627.

Oliveira, C., Dinis, M.T., Soares, F., Cabrita, E., Pousão-Ferreira, P., Sánchez-Vázquez, F.J., 2009a. Lunar and daily spawning rhythms of Senegal sole (Solea senegalensis). J. Fish Biol. 75, 61-74.

Oliveira, C., Vera, L.M., López-Olmeda, J.F., Guzmán, J.M., Mañanós, E., Ramos, J., Sánchez-Vázquez, F.J., 2009b. Monthly day/night changes and seasonal daily rhythms of sexual steroids in Senegal sole (Solea senegalensis) under natural fluctuating or controlled environmental conditions. Comp. Biochem. Physiol. Part A Mol. Integr. Physiol. 152, 168-175.

Oliveira, C., Mañanós, E., Ramos, J., Sánchez-Vázquez, F.J., 2011. Impact of photoperiod manipulation on day/night changes in melatonin, sex steroids and vitellogenin plasma levels and spawning rhythms in Senegal sole, Solea senegalensis. Comp. Biochem. Physiol. - Part A Mol. Integr. Physiol. 159, 291-295.

Oliveira, C.C.V., Aparício, R., Blanco-Vives, B., Chereguini, O., Martín, I., Javier SánchezVazquez, F., 2013. Endocrine (plasma cortisol and glucose) and behavioral (locomotor and self-feeding activity) circadian rhythms in Senegalese sole (Solea senegalensis Kaup 1858) exposed to light/dark cycles or constant light. Fish Physiol. Biochem. 39, 479-487.

Oliveira, C., Grano-Maldonado, M., Gonçalves, R., Frias, P., Sykes, A., 2017. Preliminary results on the daily and seasonal rhythms of cuttlefish Sepia officinalis (Linnaeus, 1758) locomotor activity in captivity. Fishes 2 (3), 9.

Pankhurst, N.W., 2011. The endocrinology of stress in fish: an environmental perspective. Gen. Comp. Endocrinol. 170, 265-275.

Pasquet, A., 2019. Effects of domestication on Fish behaviour. In: Teletchea, F. (Ed.), Animal Domestication. IntechOpen, pp. 91-1085.

Porta, J., Porta, J.M., Martínez-Rodríguez, G., Alvarez, M.C., 2006. Development of a microsatellite multiplex PCR for Senegalese sole (Solea senegalensis) and its application to broodstock management. Aquaculture 256 (1-4), 159-166.

R Core Team, 2018. R: A Language and Environment for Statistical Computing. R Foundation for Statistical Computing, Vienna, Austria. https://www.R-project.org/.

Redfern, J.C., Cooke, S.J., Lennox, R.J., Nannini, M.A., Wahl, D.H., Gilmour, K.M., 2017. Effects of maternal cortisol treatment on offspring size, responses to stress, and anxiety-related behavior in wild largemouth bass (Micropterus salmoides). Physiol. Behav. 180, 15-24.

Saraiva, J.L., Castanheira, M.F., Arechavala-López, P., Volstorf, J., Studer, B.H., 2019. Domestication and welfare in farmed Fish. In: Teletchea, F. (Ed.), Animal Domestication. IntechOpen, pp. 109-135.

Schreck, C.B., 2010. Stress and fish reproduction: the roles of allostasis and hormesis. Gen. Comp. Endocrinol. 165 (3), 549-556.

Singh, A.K., Lal, B., Pati, A.K., 2009. Variability in the characteristics of ultradian and circadian rhythms in plasma levels of growth hormone in the Indian walking catfish, Clarias batrachus. Biol. Rhythm Res. 40 (3), 211-221.

Small, B.C., Davis, K.B., Peterson, B.C., 2008. Elucidating the effects of cortisol and stress on economically important traits in Channel catfish. N. Am. J. Aquac. 70, 223-235.

Soares, F., Engrola, S., Dinis, M., 2002. Anomalías en la pigmentación de juveniles de lenguado Solea senegalensis Kaup, 1858. Boletín del Instituto Español de Oceanografía 18, 405-407.

Teletchea, F., Fontaine, P., 2014. Levels of domestication in fish: implications for the sustainable future of aquaculture. Fish Fish. 15, 181-195.

Tian, H.Y., Zhang, D.D., Xu, C., Wang, F., Liu, W.B., 2015. Effects of light intensity on growth, immune responses, antioxidant capability and disease resistance of juvenile blunt snout bream Megalobrama amblycephala. Fish Shellfish Immunol. 47, 674-680.

Tort, L., 2011. Impact of stress in health and reproduction. In: Farrell, A.P. (Ed.), Encyclopedia of Fish Physiology. Academic Press, Elsevier, Italy, pp. 1541-1552.

Vera, L.M., Cairns, L., Sánchez-Vázquez, F.J., Migaud, H., 2009. Circadian rhythms of locomotor activity in the Nile tilapia Oreochromis niloticus. Chronobiol. Int. 26 (4), 666-681.

Vera, L.M., Montoya, A., Pujante, I.M., Pérez-Sánchez, J., Calduch-Giner, J.A., Mancera, J.M., Moliner, J., Sánchez-Vázquez, F.J., 2014. Acute stress response in gilthead sea bream (Sparus aurata L.) is time-of-day dependent: physiological and oxidative stress indicators. Chronobiol. Int. 31, 1051-1061.

Villamizar, N., Blanco-Vives, B., Migaud, H., Davie, A., Carboni, S., Sánchez-Vázquez, F.J., 2011. Effects of light during early larval development of some aquacultured teleosts: a review. Aquaculture 315, 86-89.

Volkoff, H., Unniappan, S., Kelly, Scott P., 2009. Fish neuroendocrinology. In: first edition. In: Bernier, N.J., Van Der Kraak, G., Farrell, A.P., Brauner, C.J. (Eds.), Fish Physiology Volume 28. Academic Press, Elsevier, London, pp. 421-466.

Wang, T., Cheng, Y., Liu, Z., Yan, S., Long, X., 2013. Effects of light intensity on growth, immune response, plasma cortisol and fatty acid composition of juvenile Epinephelus coioides reared in artificial seawater. Aquaculture 414-415, 135-139. 